\title{
RNase P branches out from RNP to protein: organelle-triggered diversification?
}

\author{
Katherine C. Goldfarb, Sumit Borah, and Thomas R. Cech ${ }^{1}$ \\ Howard Hughes Medical Institute, University of Colorado Biofrontiers Institute, Boulder Colorado 80309, USA
}

RNase $P$ is the enzyme that removes $5^{\prime}$ leader sequences from precursor tRNAs. Remarkably, in most organisms, RNase $P$ is a ribonucleoprotein particle where the RNA component is responsible for catalysis. In this issue of Genes \& Development, Gutmann and colleagues (pp. 1022-1027) report the first organism, Arabidopsis thaliana, to employ protein-only RNase $P$ in both its nucleus and organelles. An intriguing possibility is that replacement of $R$ Nase $P$ ribonucleoprotein particles (RNPs) by proteins may have been triggered by the acquisition of organelles.

The endoribonuclease RNase $\mathrm{P}$ functions to remove 5' leader sequences from tRNA precursors (pre-tRNAs) post-transcriptionally. Biochemically speaking, this endoribonucleolytic cleavage event can easily be performed by enzymes with a variety of macromolecular compositions. Specifically, ribozymes, ribonucleoprotein particles (RNPs), and protein-only enzymes are all well-suited for site-specific RNA cleavage. Nevertheless, in representative species from all three domains of life-bacteria, archaea, and eukarya (Fig. 1, bottom left)-RNase P contains both RNA and protein components. While the ratio of RNA to protein components in these RNPs varies from organism to organism, it is the overwhelming presence of the ribozyme component within these RNPs that has distinguished this enzyme from the plethora of protein-centric enzymes in the modern cell.

\section{RNase $P$ as a ribonucleoprotein}

The best-studied RNase Ps are those found in bacteria, in which the enzyme consists of a single RNA of $\sim 140 \mathrm{kDa}$ and a small protein subunit of $\sim 14 \mathrm{kDa}$. In buffer conditions of high ionic strength, the RNA alone is capable of catalyzing the cleavage of pre-tRNA 5' leader sequences

[Keywords: RNase P; tRNA maturation; RNA processing; pentatricopeptide repeat; plant]

${ }^{1}$ Corresponding author.

E-mail thomas.cech@colorado.edu.

Article is online at http://www.genesdev.org/cgi/doi/10.1101/gad.193581.112. in vitro (Guerrier-Takada et al. 1983). However, in vivo and at physiological salt concentrations in vitro, the protein cofactor is essential for catalysis. The RNase P protein is thought to function in neutralizing electrostatic repulsion between RNase P RNA and pre-tRNA, increasing the affinity of the RNA subunit for pre-tRNA substrates $\sim 10^{4}$-fold (Crary et al. 1998; Kurz et al. 1998); enhancing release of the processed tRNA product and thus increasing the turnover rate of the enzyme (Reich et al. 1988; Kurz et al. 1998); expanding the repertoire of substrates recognized by RNase P to include other RNAs, such as 4.5S rRNA and 10Sa rRNA (Peck-Miller and Altman 1991; Liu and Altman 1994); and mediating dimerization of the RNase P holoenzyme (Fang et al. 2001).

In archaea, a structurally conserved RNase P RNA associates with not one but four or five different protein cofactors (Tsai et al. 2006). However, the RNA is still sufficient for catalysis at elevated salt concentrations in vitro (Pannucci et al. 1999), while none of the protein subunits has observable catalytic activity. Interestingly, the only documented organism that completely lacks an RNase P enzyme is the archaeon Nanoarchaeum equitans, an obligate symbiont of another archaeon, Ignicoccus. $N$. equitans harbors both the second smallest nonviral genome sequenced, $\sim 491 \mathrm{~kb}$, and also one of the densest in terms of coding capacity, where only $\sim 5 \%$ of the genome is not transcribed into a functional RNA (Waters et al. 2003; Randau et al. 2008). Following the compactness of its genome, the tRNAs of $N$. equitans are transcribed without $5^{\prime}$ leader sequences, which has alleviated evolutionary pressure to retain RNase P.

Continuing this trend, nuclear transcribed eukaryotic RNase P RNA has acquired even more protein cofactors than archaea, up to 10 in yeast and humans. Still, the RNA molecule from both of these organisms has been shown to be responsible for catalysis (Kikovska et al. 2007). At least four of the archaeal RNase P proteins have homologs in the representative eukaryotic nuclear RNPs (Hall and Brown 2002), although none of the archaeal or eukaryotic proteins bears homology with the lone bacterial protein. In contrast, there is clear structural similarity among the RNA subunits from bacteria, archaea, and eukaryotes (Sun and Caetano-Anolles 2010). 


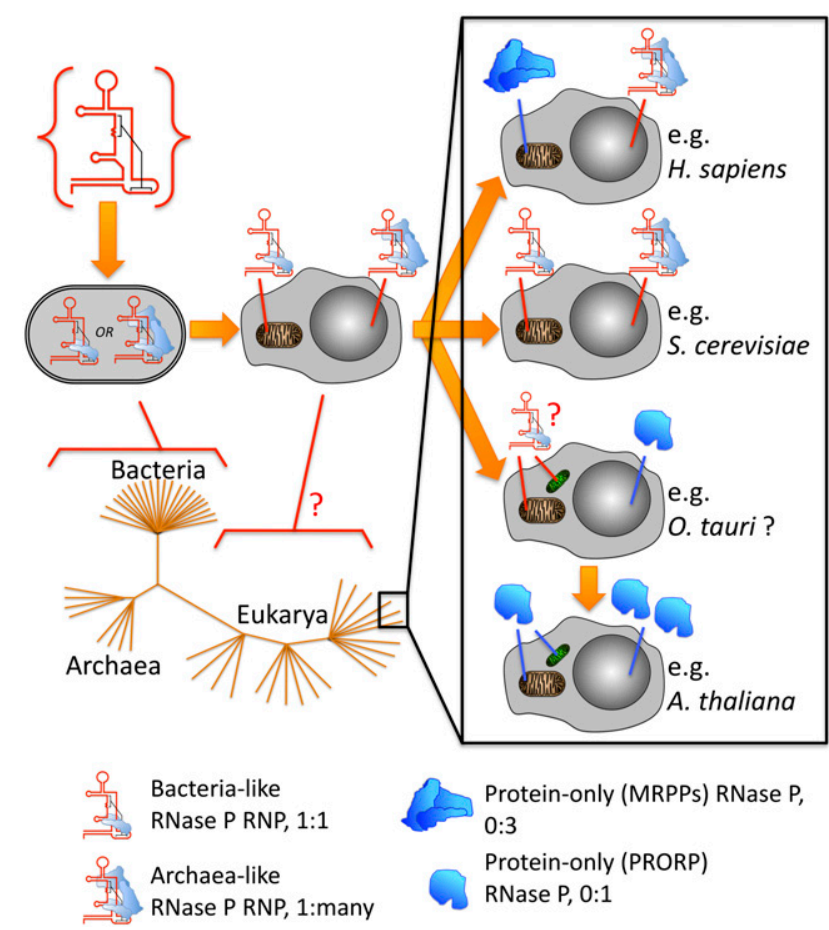

Figure 1. Evolution and diversification of RNase P. RNA (red) and protein (blue) compositions of RNase $\mathrm{P}$ across phylogeny are depicted with parsimonious evolutionary progression (orange arrows). Systems exemplifying organelle-triggered diversification are boxed at the right. RNase P RNA is shown as the minimal universal core secondary structure (Evans et al. 2006), and protein shapes are iconic throughout the figure for simplicity. The RNA: protein ratio for each RNase $\mathrm{P}$ is indicated. The universal tree (Pace 2009) at the bottom left indicates the three domains of life; note that the examples shown here reside at a remote extremity of the phylogenetic diversity currently identified.

\section{Ribozyme roots}

Despite a suggestive tendency for RNase P to accumulate more and more proteins around the RNA core of the enzyme, the fact that it is a ribozyme in representative organisms from all branches of life is noteworthy. This broad distribution supports the RNA world hypothesis, which proposes that early life was dominated by RNA molecules owing to the capability of RNA to carry genetic information as well as perform catalysis. Accordingly, the RNase P RNP has provided a glimpse into the ancient beginnings of biology, and the persistence of its catalytic RNA moiety across phylogeny has served as a molecular reminder that each organism is carrying its history. The other remnant from such a primordial world is the ribosome, a ribozyme already so well developed in the common ancestor of bacteria, archaea, and eukarya that it is accordingly easily recognizable across all contemporary forms of life.

\section{RNase Ps without RNA}

Unlike the ribosome, however, mounting evidence indicates that RNase P enzymes do not always contain an essential, catalytically active RNA component. Specifically, although all bacterial and archaeal RNase Ps appear to function as ribozymes within RNPs, some eukaryotic RNase Ps lack an RNA component entirely. For example, Wang et al. (1988) observed that the RNase P activity in spinach chloroplasts was quite different from that of conventional bacterial RNase P. First, it had a buoyant density in a cesium chloride gradient similar to that of protein, whereas RNase P activity in bacterial lysate had a buoyant density more similar to RNA. Furthermore, spinach chloroplast RNase $\mathrm{P}$ was shown to be resistant to pretreatment with micrococcal nuclease, whereas bacterial RNase P was completely inactivated by such treatment. Additional studies later revealed that spinach chloroplast RNase $\mathrm{P}$ is a fundamentally different catalyst than bacterial RNase P. When the phosphodiester backbone of a precursor tRNA was substituted at the cleavage site by a phosphorothioate moiety, cleavage by bacterial RNase P RNA was inhibited 1000-fold, while spinach chloroplast RNase P was unaffected, suggesting that the two enzymes employ different catalytic mechanisms (Thomas et al. 2000). Other studies had implicated an $\sim 70-\mathrm{kD}$ protein as the RNase $\mathrm{P}$ enzyme in spinach chloroplasts (Thomas et al. 1995).

More recently, RNase P from another organelle, the human mitochondrion, was demonstrated to be comprised of three proteins (MRPP1, MRPP2, and MRPP3) and to completely lack an RNA component (Holzmann et al. 2008). Although all three proteins are required for activity, the MRPP3 subunit contains a putative metallonuclease domain and is thought to provide the active site for catalysis. All MRPP proteins are encoded in the nuclear genome of the human cell and post-translationally imported into the mitochondria. There appears to be no homology between the MRPP proteins and the protein components of the nuclear human RNase P RNP, which consists of a single RNA and 10 protein cofactors. This indicates that the mitochondrial, protein-only RNase $\mathrm{P}$ evolved independently from the nuclear enzyme. Interestingly, it appears that despite the presence of a protein-only RNase P within the mitochondria, the RNA subunit of the nuclear enzyme is still imported into the mitochondrial matrix (Wang et al. 2010; Mercer et al. 2011). Whether this RNA component is enzymatically active inside of the mitochondria is not yet known.

The identification of protein components of the mitochondrial RNase $\mathrm{P}$ in humans prompted Giegé and colleagues (Gobert et al. 2010) to characterize an MRPP3 homolog in the mitochondria and chloroplasts of Arabidopsis thaliana. This protein, called PRORP1 (proteinaceous RNase P 1), also serves as an RNA-free RNase P enzyme in these organelles. Remarkably, the $A$. thaliana PRORP1 protein was shown to rescue viability of Escherichia coli harboring a lethal mutation in the RNA subunit of RNase $\mathrm{P}$, demonstrating complementation of an ancient ribozyme by its modern protein-only counterpart. Building on these findings, Giegé and colleagues (Gutmann et al. 2012) report in this issue of Genes \& Development that two other PRORP proteins (PRORP2 and PRORP3) also function as RNase Ps in A. thaliana. 
This finding has elevated impact because PRORP2/3 are shown to function in the A. thaliana nucleus, and accordingly, this report is the first of an entire organism that employs protein-only RNase P activity for all of its tRNAutilizing compartments. Knockdown of organellar PRORP1 is demonstrated to result in defects in chloroplast and mitochondrial pre-tRNA maturation, changes in organellar structure, and yellowing of leaves, whereas depletion of nuclear PRORP2/3 results in defects in nuclear pre-tRNA maturation and leaf senescence. Interestingly, although PRORP proteins have been documented in many different eukaryotes, they are not found in bacteria or archaea (Gobert et al. 2010).

\section{Why did RNase P lose its RNA in some eukaryotes? An organelle-triggered hypothesis}

The comparatively simple progression from the ancestral "RNA-only" RNase P to the bacterial and archaeal RNase P RNPs (Fig. 1, left) is strikingly juxtaposed with the variety of RNase $\mathrm{P}$ compositions observed in eukaryotic systems (Fig. 1, boxed at right). Can we glean any insight from the coincidence of eukaryotic emergence and the explosion of RNase P diversity? The following points highlight a hypothesis whereby the introduction of endosymbiotic organelles triggered the diversification of eukaryotic RNase P enzymes.

(1) Acquisition of membrane-bound compartments necessitates novel functionality. The division of eukarya is marked foremost by the compartmentalization of the intracellular milieu, most notably the separation of genetic material by a nuclear membrane. This revolutionary physical demarcation within the primitive eukaryotic cell was temporally coupled with the endosymbiosis of $\alpha$-proteobacteria-like ancestors to form mitochondria and ancient cyanobacteria to form chloroplasts (Timmis et al. 2004; van der Giezen 2011). Thus, along with unprecedented requirements for trafficking between nuclear, cytoplasmic, and organellar compartments, the early eukaryotic cell was charged with the coevolution of multiple autonomously replicating genomes within its plasma membrane. Furthermore, since nuclear and organellar genomes all encoded their own pre-tRNAs, each compartment would require RNase P activity. This could be fulfilled either by expressing RNase $\mathrm{P}$ components from the genome within that compartment or via import of these components from another compartment. Accordingly, and perhaps not by chance, the novel functional demand of compartmentalization coincided with a handy boost in genetic capacity from the additional genomes.

(2) Endosymbiotic redundancy mimics gene duplication. The situation of two or more autonomously replicating genomes within a single eukaryotic cell is potentially analogous to a gene duplication event whereby a host gene could temporarily cover functionality of a particular organellar gene product. For example, the nuclear-encoded RNase P RNP could be imported into the organelle, relieving selective pressure to retain organelle-encoded RNase P components. This would provide an opportunity for the organellar components to be lost, and the simultaneous variation of an independent gene product with similar properties (e.g., a proteinaceous ribonuclease-like PRORP) could complement this lost functionality.

(3) Organellar genome compaction could enable molecular diversification. Since a general evolutionary penchant is efficiency, there would be no selective pressure to maintain the intergenome redundancy following endosymbiosis. Consequently, upon deletion of the temporary duplicate (e.g., inefficient import of a key component of the nuclear RNase P RNP), any new functionality (e.g., PRORP) obtained during this selective reprieve might be immediately required by the cell, evolutionarily speaking. At this point, selective pressure would be high to optimize the innovatively used gene product, thus resulting in a dispersion of functionality prompted by endosymbiosis (Fig. 1, boxed at right).

The following inspection of those select few eukaryotic systems that have been functionally characterized to date provides support for such an "organelle-triggered molecular diversification" hypothesis. (While multiple in silico studies have identified RNase P RNAs in the nucleus [Marquez et al. 2005] or organelles [Seif 2003; Seif et al. 2005 ] in a broad range of eukaryotes, experiments demonstrating that these components are actually functional have not been performed, and thus these studies are not discussed here.)

Saccharomyces cerevisiae and Homo sapiens: ancient nuclear systems, mitochondria as suggestive intermediates

The nuclear components of human and S. cerevisiae RNase $\mathrm{P}$ were the first to be well characterized and, concurrently, the most easily traceable to the ancient RNP progression. Each of these systems includes a single RNA component that is structurally conserved with the bacterial RNA and up to 10 protein subunits, four of which are clearly homologous to four archaeal protein subunits.

The complexity and shear bulk of these nuclear RNPs could present a challenge for their complete import into mitochondria whose genomes no longer encode RNase $\mathrm{P}$ components. In S. cerevisiae, the RNA component of the mitochondrial enzyme is encoded by the mitochondrial genome (Hollingsworth and Martin 1986), while its sole protein component (RMP2) is nucleus-encoded and of a lineage independent from that of the protein subunits found in the nuclear enzyme (Fig. 1, right; Morales et al. 1992). It is therefore plausible that when the gene for this yeast's mitochondrial RNase P protein migrated to the nucleus, the temporary duplication and subsequent deletion of the mitochondrial gene resulted in supplementation by RMP2. In contrast, human mitochondria have lost the locus for RNase P RNA in their genomes and instead 
appear to import a patchwork proteinaceous enzyme comprised of MRPP1, MRPP2, and MRPP3 (Fig. 1, top right). This still-evolving (see below) three-protein system may have been selected to combat the costly import of the entire nuclear RNP when both RNA and protein components were lost from the mitochondrial genome. Indeed, the fact that human nuclear RNase P RNA is still efficiently imported into mitochondria, despite strong evidence that it does not currently participate in mitochondrial tRNA maturation (Wang et al. 2010; Mercer et al. 2011), supports this intermediate phase.

\section{A. thaliana: a complete transition to protein, remnant duplication}

The latest work by Giegé and colleagues (Gutmann et al. 2012) demonstrates protein-only RNase P activity in the nuclei, mitochondria, and chloroplasts of the representative land plant $A$. thaliana (Fig. 1, bottom right). Here, we have a novel example where the ancient RNP components have vanished from the modern organism, and the functional RNase P is none other than a homolog of the putative catalytic subunit of the human mitochondrial proteinaceous enzyme. Thus, RNase $\mathrm{P}$ in A. thaliana is a clear example of an efficient protein that has usurped RNA-based or RNP-based function. Furthermore, PRORP evolution is still progressing, as evidenced by the apparent functional redundancy of PRORP2/ PRORP3 in the nucleus.

\section{Why did the PRORPs evolve to replace RNPs in plants?}

Whereas animal cells harbor only mitochondria, plant cells contain both mitochondria and chloroplasts. It is tempting to credit the existence of multiple membranebound, genome-containing organelles (Bhattacharya et al. 2004) in the plant lineage as the reason why the plant PRORP proteins evolved to functionally replace the RNase P RNP. Nominally, acquisition of each organelle (mitochondrial, chloroplast, secondary chloroplast, etc.) could provide an additional opportunity for rapid diversification. A clue that PRORP's RNase P functionality may have evolved due to organelle-triggered expansion lies with the primitive alga Ostreococcus tauri, where functional PRORP and bacteria-like RNase P proteins are present in the nucleus, with an apparently nonfunctional RNase P RNA encoded in each organelle (Fig. 1, middle right; Lai et al. 2011). The brief coexistence of host and endosymbiont RNase P RNPs could have enabled the PRORP protein to partially take over RNase $\mathrm{P}$ function in both compartments of this primitive plant species. The homology between the PRORPs and MRPP3 may provide further evidence that the human mitochondrial enzyme represents an intermediate stage where MRPP3 has not yet evolved to function autonomously. Alternatively, MRPP3 could have acquired its patchwork partners for additional specificity. Either way, the exclusive presence of PRORP homologs in organelle-containing eukaryotes, coupled with their suggestive coexistence alongside various permutations of
RNase P RNPs, supports PRORP evolution by organelletriggered molecular diversification.

\section{Concluding remarks}

Many previous reviews (Evans et al. 2006; Lai et al. 2010) have concluded with the question of why the RNA nature of RNase $\mathrm{P}$ has persevered so remarkably in the proteindominated modern world. What is so special about RNase $P$ that present day biology is so densely sprinkled with vestiges of its ancient self? Why is a remnant of that original RNase P RNA one of the final genes (Burger et al. 2012) that an autonomously replicating organelle can bear to relinquish? Why are land plants the only group to date that has completely escaped this inexplicably ubiquitous RNA-based mechanism?

While satisfying resolutions to these probing questions remain nominally elusive, strong data, such as that of Giegé and colleagues (Gobert et al. 2010; Gutmann et al. 2012), have invigorated their pursuit. Is it possible that yet uncharacterized RNase Ps are no longer RNPs in other eukaryotes? Certainly, the current sample size is small; many more and broader investigations of eukaryotic systems are needed to substantiate the trends depicted in Figure 1. Future work in more dispersed lineages will inform the flow of evolution through this spectrum.

More generally, might the finding that some eukaryotes have replaced RNase $\mathrm{P}$ ribozymes with protein enzymes mean that RNA-based enzymes in general are on their way out? Certainly not. Although some eukaryotes have lost the RNA component of RNase P, all eukaryotes have gained other, even more complex RNP enzymes - the spliceosome and telomerase (Cech 2009). This suggests that RNP enzymes are still evolving new functionality and will continue to be vibrant contributors to biological catalysis.

\section{Acknowledgments}

We thank Dr. Norm Pace (University of Colorado at Boulder) for comments. K.C.G. is supported by NIH Molecular Biophysics Training Grant T32 GM-065103. T.R.C is an investigator, and S.B. is a post-doctoral associate of HHMI.

\section{References}

Bhattacharya D, Yoon HS, Hackett JD. 2004. Photosynthetic eukaryotes unite: Endosymbiosis connects the dots. BioEssays 26: $50-60$.

Burger G, Jackson C, Waller RF. 2012. Unusual mitochondrial genomes and genes. In Organelle genetics (ed. CE Bullerwell), pp. 41-76. Springer, Berlin.

Cech TR. 2009. Crawling out of the RNA world. Cell 136: 599602.

Crary SM, Niranjanakumari S, Fierke CA. 1998. The protein component of Bacillus subtilis ribonuclease $\mathrm{P}$ increases catalytic efficiency by enhancing interactions with the $5^{\prime}$ leader sequence of pre-tRNAAsp. Biochemistry 37: 9409-9416.

Evans D, Marquez SM, Pace NR. 2006. RNase P: Interface of the RNA and protein worlds. Trends Biochem Sci 31: 333-341.

Fang XW, Yang XJ, Littrell K, Niranjanakumari S, Thiyagarajan P, Fierke CA, Sosnick TR, Pan T. 2001. The Bacillus subtilis 
RNase P holoenzyme contains two RNase P RNA and two RNase $\mathrm{P}$ protein subunits. RNA 7: 233-241.

Gobert A, Gutmann B, Taschner A, Gossringer M, Holzmann J, Hartmann RK, Rossmanith W, Giegé P. 2010. A single Arabidopsis organellar protein has RNase P activity. Nat Struct Mol Biol 17: 740-744.

Guerrier-Takada C, Gardiner K, Marsh T, Pace N, Altman S. 1983. The RNA moiety of Ribonuclease $\mathrm{P}$ is the catalytic subunit of the enzyme. Cell 35: 849-857.

Gutmann B, Gobert A, Giegé P. 2012. PRORP proteins support RNase P activity in both organelles and the nucleus in Arabidopsis. Genes Dev (this issue). doi: 10.1101/gad.189514.112.

Hall TA, Brown JW. 2002. Archaeal RNase P has multiple protein subunits homologous to eukaryotic nuclear RNase P proteins. RNA 8: 296-306.

Hollingsworth MJ, Martin NC. 1986. RNase P activity in the mitochondria of Saccharomyces cerevisiae depends on both mitochondrion and nucleus-encoded components. Mol Cell Biol 6: 1058-1064.

Holzmann J, Frank P, Loffler E, Bennett KL, Gerner C, Rossmanith W. 2008. RNase P without RNA: Identification and functional reconstitution of the human mitochondrial tRNA processing enzyme. Cell 135: 462-474.

Kikovska E, Svard SG, Kirsebom LA. 2007. Eukaryotic RNase P RNA mediates cleavage in the absence of protein. Proc Natl Acad Sci 104: 2062-2067.

Kurz JC, Niranjanakumari S, Fierke CA. 1998. Protein component of Bacillus subtilis RNase P specifically enhances the affinity for precursor-tRNAAsp. Biochemistry 37: 23932400 .

Lai LB, Vioque A, Kirsebom LA, Gopalan V. 2010. Unexpected diversity of RNase $\mathrm{P}$, an ancient tRNA processing enzyme: Challenges and prospects. FEBS Lett 584: 287-296.

Lai LB, Bernal-Bayard P, Mohannath G, Lai SM, Gopalan V, Vioque A. 2011. A functional RNase $P$ protein subunit of bacterial origin in some eukaryotes. Mol Genet Genomics 286: 359-369.

Liu F, Altman S. 1994. Differential evolution of substrates for an RNA enzyme in the presence and absence of its protein cofactor. Cell 77: 1093-1100.

Marquez SM, Harris JK, Kelley ST, Brown JW, Dawson SC, Roberts EC, Pace NR. 2005. Structural implications of novel diversity in eucaryal RNase P RNA. RNA 11: 739-751.

Mercer TR, Neph S, Dinger ME, Crawford J, Smith MA, Shearwood AM, Haugen E, Bracken CP, Rackham O, Stamatoyannopoulos JA, et al. 2011. The human mitochondrial transcriptome. Cell 146: 645-658.

Morales MJ, Dang YL, Lou YC, Sulo P, Martin NC. 1992. A $105-\mathrm{kDa}$ protein is required for yeast mitochondrial RNase $\mathrm{P}$ activity. Proc Natl Acad Sci 89: 9875-9879.

Pace NR. 2009. Mapping the tree of life: Progress and prospects. Microbiol Mol Biol Rev 73: 565-576.

Pannucci JA, Haas ES, Hall TA, Harris JK, Brown JW. 1999. RNase P RNAs from some Archaea are catalytically active. Proc Natl Acad Sci 96: 7803-7808.

Peck-Miller KA, Altman S. 1991. Kinetics of the processing of the precursor to $4.5 \mathrm{~S}$ RNA, a naturally occurring substrate for RNase P from Escherichia coli. J Mol Biol 221: 1-5.

Randau L, Schroder I, Soll D. 2008. Life without RNase P. Nature 453: 120-123.

Reich C, Olsen GJ, Pace B, Pace NR. 1988. Role of the protein moiety of ribonuclease $\mathrm{P}$, a ribonucleoprotein enzyme. Science 239: 178-181.

Seif ER. 2003. Mitochondrial RNase P RNAs in ascomycete fungi: Lineage-specific variations in RNA secondary structure. RNA 9: 1073-1083.
Seif E, Leigh J, Liu Y, Roewer I, Forget L, Lang BF. 2005. Comparative mitochondrial genomics in zygomycetes: Bacterialike RNase P RNAs, mobile elements and a close source of the group I intron invasion in angiosperms. Nucleic Acids Res 33: 734-744.

Sun FJ, Caetano-Anolles G. 2010. The ancient history of the structure of ribonuclease $\mathrm{P}$ and the early origins of archaea. BMC Bioinformatics 11: 153. doi: 10.1186/1471-2105-11-153.

Thomas BC, Gao L, Stomp D, Li X, Gegenheimer PA. 1995. Spinach chloroplast RNase P: A putative protein enzyme. Nucleic Acids Symp Ser 33: 95-98.

Thomas BC, Li X, Gegenheimer P. 2000. Chloroplast ribonuclease $\mathrm{P}$ does not utilize the ribozyme-type pre-tRNA cleavage mechanism. RNA 6: 545-553.

Timmis JN, Ayliffe MA, Huang CY, Martin W. 2004. Endosymbiotic gene transfer: Organelle genomes forge eukaryotic chromosomes. Nat Rev Genet 5: 123-135.

Tsai HY, Pulukkunat DK, Woznick WK, Gopalan V. 2006. Functional reconstitution and characterization of Pyrococcus furiosus RNase P. Proc Natl Acad Sci 103: 16147-16152.

van der Giezen M. 2011. Mitochondria and the rise of eukaryotes. Bioscience 61: 594-601.

Wang MJ, Davis NW, Gegenheimer P. 1988. Novel mechanisms for maturation of chloroplast transfer RNA precursors. EMBO I 7: 1567-1574.

Wang G, Chen HW, Oktay Y, Zhang J, Allen EL, Smith GM, Fan KC, Hong JS, French SW, McCaffery JM, et al. 2010. PNPASE regulates RNA import into mitochondria. Cell 142: 456-467.

Waters E, Hohn MJ, Ahel I, Graham DE, Adams MD, Barnstead M, Beeson KY, Bibbs L, Bolanos R, Keller M, et al. 2003. The genome of Nanoarchaeum equitans: Insights into early archaeal evolution and derived parasitism. Proc Natl Acad Sci 100: 12984-12988. 


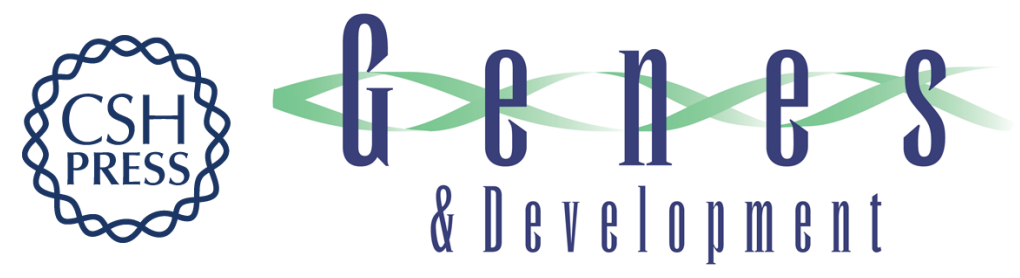

\section{RNase P branches out from RNP to protein: organelle-triggered diversification?}

Katherine C. Goldfarb, Sumit Borah and Thomas R. Cech

Genes Dev. 2012, 26:

Access the most recent version at doi:10.1101/gad.193581.112

Related Content

References License

Email Alerting Service
PRORP proteins support RNase $P$ activity in both organelles and the nucleus in Arabidopsis

Bernard Gutmann, Anthony Gobert and Philippe Giegé

Genes Dev. May, 2012 26: 1022-1027

This article cites 34 articles, 13 of which can be accessed free at:

http://genesdev.cshlp.org/content/26/10/1005.full.html\#ref-list-1

Articles cited in:

http://genesdev.cshlp.org/content/26/10/1005.full.html\#related-urls

Receive free email alerts when new articles cite this article - sign up in the box at the top right corner of the article or click here.

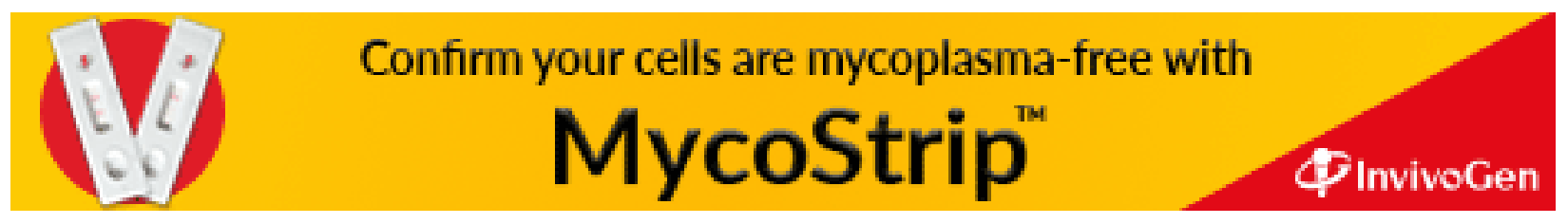

